\title{
Social Capital, Place Meanings, and Perceived Resilience to Climate Change*
}

\author{
Jordan W. Smith \\ Purdue University \\ Dorothy H. Anderson \\ North Carolina State University \\ Roger L. Moore \\ North Carolina State University
}

\begin{abstract}
This research analyzes individuals' perceived resilience to changing climatic conditions. Specifically, we suggest individual resilience is composed of an awareness of localized risks created because of climate change, a willingness to learn about, and plan for, the potential impacts of altered environmental conditions, and general appraisals of personal adaptive capacities. We hypothesize that resilience is influenced by the characteristics of individuals' social networks and also by their social-psychological dependence on local environments. Using data collected in three resourceassociated communities within the southeastern United States, our analysis suggests bonding ties may limit individuals' willingness to seek new information about the potential impacts of climate change. Conversely, the data suggest the use of a diverse array of bridging ties is positively associated with information-seeking behavior. The data also support our hypothesis that individuals' social psychological dependencies on the local environment influences their perceived resilience to changing climatic conditions. By gaining a clearer understanding of how individuals' social networks and social-psychological dependencies affect their perceived ability to adapt to changing environmental conditions, decision makers can focus on policy solutions that increase adaptive capacities and build social resilience.
\end{abstract}

\section{Introduction}

The potential impacts of global climate change has captured the attention of citizens, policymakers, industry, and the scientific research community. Since the establishment of the Intergovernmental Panel on Climate Change in 1988 the human causes and consequences of climate change have become more apparent. In turn, many natural and physical

* This research was supported by a doctoral dissertation improvement grant from the National Science Foundation (Award No. 1030395) and a Hofmann Fellowship from the College of Natural Resources at North Carolina State University. We thank Dr. Ed Kick, Dr. Hugh Devine, and Hollie Smith for their comments and suggestions. Correspondence should be addressed to Jordan W. Smith, Purdue University, Department of Forestry and Natural Resources (FORS 201A), 195 Marsteller Street, West Lafayette, IN 47907-2061, e-mail smit1547@purdue.edu. 
science research agendas have become increasingly focused on addressing the problem. However, research from the social sciences, and sociology in particular, has been "slow to engage the topic of global climate change in their research" (Nagel, Dietz, and Broadbent 2009:9). In recent years, however, social science research focused on climate change has increased rapidly. Specific calls for sociological inquiry on climate change have been made by both the National Science Foundation (Nagel et al. 2009) and the National Academy of Science (NAS) (Brewer 2009). Specifically, the NAS Committee on Human Dimensions of Global Climate Change has called for more directed inquiry on how humans perceive and respond to global climate change (Brewer 2009). Climate change cannot be addressed, either scientifically or pragmatically, with an understanding of physical processes alone. A more holistic understanding is needed and can emerge if social science methods and theories are used to develop a clearer understanding of the complex social, cultural, and behavioral realities of the impacts of climate change and individuals' ability to adapt to those impacts.

This research assists in filling this need by analyzing individuals' perceived ability to adapt to changing climatic conditions. An individual's ability to adapt to changing climatic conditions is influenced by myriad biophysical, political, social, and psychological factors. We examine two specific social and psychological factors believed to influence adaptive capacities. The factors under examination are (1) social capital, individuals' ability and willingness to obtain access to information and resources through their existing social ties, and (2) place-based social-psychological dependencies, the specific meanings that individuals ascribe to geographic spaces. These social and psychological factors can, and do, play an important role in climate change adaptation (Marshall, Gordon, and Ash 2011).

\section{Resilience}

Resilience is a concept that has its origins in the field of ecology (e.g., Holling 1973) and, at least implicitly, in the works of early sociologists concerned with the indivisibility of social organization and ecological production (e.g., Duncan 1959, 1961; Hawley 1950). While the primary concern of early social scientists was to understand how altered ecological conditions shaped changes in the organization of social groups and societies, we are primarily concerned with individual-level responses to ecological change. The term "resilience" in this research refers explicitly to the flexibility through which individuals can cope with and adapt to changes in environmental conditions. Resilient individuals are flexible 
and prepared for change and uncertainty, and they are essential for societies to prosper in the face of unknown circumstances (Folke et al. 2002; Gunderson 1999; Hughes et al. 2005).

General resilience theory, which is a component of the larger framework of complex systems theory, suggests that resilience is defined by (1) the amount of disturbance a system can absorb and still retain the same structure and function, (2) the degree to which the system is capable of self-organization, and (3) the degree to which the system can build and increase the capacity for learning and adaptation (Carpenter and Gunderson 2001; Folke et al. 2002; Holling 1973; Nelson, Adger, and Brown 2007). Building from this theory, Marshall and colleagues (Marshall et al. 2007; Marshall et al. 2009) hypothesized that individual resilience to environmental change could be roughly mapped out with these three defining characteristics. Using resilience theory as a guide, Marshall and colleagues identified four distinct components of individual resilience to changing environmental conditions: (1) the perception of risk associated with change; (2) the perception of the ability to plan, learn, and reorganize; (3) the perception of the proximity to the threshold of coping; and (4) the level of interest in change. This research builds on that of Marshall et al.'s by adapting these four distinct components of individual resilience.

\section{Social Capital and Individual Resilience}

An individual's resilience to the impact of climate change is not a solitary process, rather it is a social one involving "the interdependence of agents through their relationships with each other, with the institutions in which they reside, and with the resource base on which they depend" (Adger 2003:388). The nature of these relationships is central to sociology and highlights a tangible area where sociological theory can be used to address global climate change (Frank 2009).

Given that adaptation processes are primarily social and involve individuals drawing on collective social resources, an individual's stock of social capital might prove important in determining his or her ability to adapt to climate change. Social capital is most generally understood as "the information, trust, and norms of reciprocity inhering in one's social networks" (Woolcock 1998:153). This is perhaps the most general definition of the construct and operates devoid of an intellectual history.

Given the purposes of the proposed research, we follow the work of Bourdieu (1986), Coleman (1988, 1990), and Woolcock (2003) by conceptualizing social capital as the stock of resources (i.e., ideas, information, and support) available to individuals through their own social ties. 
Bourdieu (1986:248) notes that "social capital is the aggregate of the actual or potential resources which are linked to possession of a durable network of more or less institutionalized relationships of mutual acquaintance and recognition-or in other words, to membership in a group." Bourdieu also contends that the existence of a network of connections is not a natural given. Rather, individuals' social ties, and in turn the aggregate level of social capital held within a network, are the product of "endless efforts at institution" (1986:249). More explicitly, individuals engage in specific kinds of behavior and seek out certain social relationships to gain access to desired resources (e.g., information, status, wealth) that are shared collectively by other social groups. Through the process of seeking out and establishing these connections, individuals eventually become embedded in a larger social structure and the collective social capital of that structure grows as a result. Bourdieu also notes that the institutionalization of social relationships results in two related outcomes. First, relationships tend to become formalized through organizations, which guarantee specific rights, and second, relationships tend to become imbued with objective feelings (e.g., gratitude, respect, friendship).

Several important conclusions can be drawn from this perspective on social capital. First, social capital involves objective associations between individuals and second, these associations involve feelings of reciprocity, trust, and positive emotion (Paxton 1999). Regarding the first point, Paxton (1999:93) points out that this is a physical reality of social connections, "there must be an objective network structure linking individuals." The second point speaks more to the content of social ties as opposed to their quantity. In the subsequent section, we further explore the two components of social capital as conceptualized for this research-objective social ties and trust.

\section{Objective Social Ties}

The first major component of social capital involves the objective ties between individuals, that is, their associations with one another. Paxton (1999) notes that associations between individuals fall into one of two types: informal social ties such as friendships and work relationships and formal group ties through associations and organizations. We consider both types of objective social ties in this research.

Informal ties. All individuals in society are embedded in their own social networks. These networks consist of numerous ties to other individuals. Each of these ties exists between the individual and others whom the individual knows, either through leisure or work activities (Wasser- 
man and Faust 1994). Furthermore, each of these ties is imbued with histories and memories of interaction between the two individuals. Accompanying these histories and meanings are emotions and feelings of personal connection. The emotions and meanings associated with each of these ties have direct implications for the total stock of social capital available to an individual. Fundamentally, one of the guiding drivers of social capital theory is the type of affective meanings ascribed to individuals' social ties. It is generally understood that individuals' informal friendships, whether they be with old schoolmates, fellow workers, or friends of friends, can create social capital through increased communication, diffusion of information, and social support (Paxton 1999).

Formal group ties. Individuals can also be tied to others through involvement in formal associations or organizations. Formal group ties differ from the aforementioned informal ties in two distinct ways. First, individuals involved in formal associations or organizations are linked not just to others with whom they share affective bonds but to dissimilar others through their joint presence at associational events and gatherings (Breiger 1974). For formal associations and organizations to survive, they must continually recruit and maintain members; that is, they must exist beyond specific social networks. Given this condition, the second point of distinction arises: through associational or organizational ties, individuals have access not only to their informal ties within the association but also to a host of ties outside their informal social networks. As Paxton points out, it is access to these additional individuals that can provide the resources for individuals "to solve collective problems and pursue specific goals" (1999:100).

\section{Trust}

"Most social capital theory is driven by discussions of trust," Paxton comments (1999:98). Trust, like social capital in general, requires the presence of social ties and requires them to be imbued with strong emotional feelings of reciprocity. More specifically, Barber (1983:165) defines trust as "socially learned and socially confirmed expectations that people have of each other, of the organizations and institutions in which they live, and the natural and moral social orders that set the fundamental understandings for their lives."

The function of trust in social ties is fairly straightforward. For both the trustees and the trustors, it enables them to engage in actions that otherwise would not have been possible (Coleman 1990). The placement of trust enables trustees to take actions that suit their needs and 
desires; likewise, it may give trustors access to trustees' resources or allow trustors to fulfill a moral imperative. The decision to place trust is contingent on individual actors' motivations and needs. Trust is embedded in contextual influences and the social location of the individual actors involved. Existing power structures, individuals' access to resources and information, and their personal and cultural histories are all factors influencing individuals' decision to place trust in others (Coleman 1990).

The theoretical importance of trust, at least for our purposes, is that it enables individuals to engage in actions that otherwise would not have been possible without its presence. An individual's resilience-in the case of this research, the risk the individual associates with climate change, the individual's willingness to learn and plan, and the individual's interest in changing behavior-may all be influenced by the extent to which that individual trusts others.

In summation of the two components of social capital, objective social ties and trust, existing social theory suggests that both might have direct consequences for how individuals are able to adapt to changing environmental conditions. The direction with which they affect adaptive capacities, however, is largely undefined, as the following section illustrates.

\section{Social Capital as an Impediment to Resilience?}

The review of the social capital literature above might seem to imply that access to social capital could only enhance individuals' adaptive capacities. But some forms of social capital may actually reduce individuals' willingness to adapt to climate change. More explicitly, the social ties that bind individuals to others in social networks can be defined as "bonding" or "bridging" ties (Gittell and Vidal 1998; Putnam 2000).

Bonding ties are relations between family members, friends, and neighbors in closed, tightly connected networks. Bonding social capital can create dense network structures and strong but localized trust. As a result, it can impose strict social norms that discourage change and foster increased homophily, the tendency of a group to become less diverse over time. Bonding ties, although needed to provide trust, can reduce a group's diversity, and thus decrease resilience by limiting an individual's set of options to those that will be accepted by the group (Portes 1998). In short, bonding social capital can hinder resilience by either cutting off individuals from needed information or imposing social norms that discourage innovation and adaptation. Previous research supports this proposition; Marshall et al. (2011) found the extent of agricultural landowners' informal social networks was 
negatively related to their willingness to consider climate forecasts in grazing decisions.

Conversely, bridging ties give access to resources and opportunities in one network to a member of another network (Granovetter 1973). Bridging social capital allows individuals access to outside information and helps them act beyond the constraints of social norms with support from outside the local network. Bridging social capital can facilitate the acquisition of needed resources and knowledge from extracommunity networks that are required to successfully adapt to changing environmental conditions, consequences, and policies. Existing research also supports this proposition; several studies have found individuals with more extensive formal social networks are more likely to have the opportunity to learn about potential adaptation behavior (Howden et al. 2007; McAllister et al. 2006).

We differentiate between bonding and bridging social capital and analyze how each independently influences individuals' resilience to climate change.

\section{Place Meanings}

While the role of social capital in individuals' level of resilience to climate change is a paramount question for sociologists, one also needs to consider the place-based social-psychological factors that may enhance or inhibit an individual's willingness to adapt to changing environmental conditions. These place-based social-psychological factors are specific meanings that individuals ascribe to geographic spaces (Tuan [1974]1990). The specific meanings individuals attach to geographic spaces range from the utilitarian and instrumental (e.g., if the space is the only place to engage in a particular activity) to the intangible and affective (e.g., if the space provides a sense of identity). In this research, we examined a set of seven distinct place meanings - individual identity, family identity, self-efficacy, self-expression, community identity, economic meaning, and ecological meaning. Previous research has discerned that these place meanings are empirically valid and generalizable across varied social and geographic settings (Smith et al. 2011). Each type of meaning is a relatively distinct way individuals ascribe importance or significance to the landscape.

Individual identity represents the extent to which individuals believe a particular place informs their self-identity. More explicitly, self-identity is a set of beliefs about an individual's personal appraisal of him- or herself as well as the individual's appraisals of how others view him or her (Proshansky, Fabian, and Kaminoff 1995). 
Family identity extends the concept of individual place identity; the concept represents the extent to which individuals believe a specific physical setting or landscape has defined their beliefs about who their family is and how others perceive them (Smith et al. 2011, 2012). If an individual believes intrafamilial social bonds require the presence of a particular physical landscape to be maintained, the family's identity is highly dependent on the presence and management of that landscape.

Self-efficacy refers to the meanings associated with realizing desired experiences in a particular setting or landscape (Smith et al. 2011, 2012). Specific to managed resource areas, desired experiences typically involve participation in preferred recreational activities (e.g., Kyle et al. 2003; Williams et al. 1992); however, they can also be generalized into broad sets of desired experiences that occur in a setting (Jorgensen and Stedman 2001, 2006). We follow Jorgensen and Stedman in our conceptualization and analysis of the meanings generated from individuals' behavioral connections to a setting. ${ }^{1}$

Self-expression refers to the meanings associated with how a particular landscape enables individuals to express themselves (Smith et al. 2011, 2012); it involves the ability of a landscape to facilitate the communication of one's self-identity. In the southern Appalachians, for example, many residents identify strongly with the forest because of its role in the region's cultural history (Salstrom 1997). In turn, the preservation of many southern Appalachian forests enables residents to retell stories of the region's history and development. The presence of the forest, in short, enables residents to express, and retain, a portion of their personal self-identity.

Just as the family identity construct extended the concept of individual identity to family, the community identity construct extends it further to encompass individuals' appraisals of what they believe their community is and how outsiders view it. The community identity construct encompasses meanings associated with local character and culture.

The sixth and seventh types of place meanings are economic meanings and ecological meanings. Economic meanings refer to individuals' appraisals of how economically dependent their community is on a particular landscape while ecological meanings refer to individuals' beliefs about how dependent their local ecosystem is on that same landscape (Smith et al. 2011, 2012).

\footnotetext{
${ }^{1}$ Jorgensen and Stedman and many other scholars classify these meanings as place dependence. Our conceptualization draws on the same theory and psychometric instruments and therefore we suggest the concepts are analogous to one another.
} 
Place-based social-psychological meanings can enhance or inhibit an individual's willingness to adapt to changing environmental conditions. Marshall et al. (2011) found that a unidimensional construct of "attachment to place" was negatively related to individuals' level of interest in adapting their behavior. A logical hypothesis would suggest that individuals who ascribe stronger and more varied meanings to the natural landscapes surrounding their communities would be (1) more cognizant of the risks global climate change poses for those landscapes, (2) more willing to learn about those risks and (3) more willing to make plans to adapt to altered future conditions, and as a result (4) believe they are more capable of adapting than other individuals.

\section{Hypotheses}

The summary of previous research above suggests that a broad range of social and psychological factors influence individuals' resilience to climate change. However, little empirical work has either conceptualized or empirically evaluated the construct of individual resilience. This research begins to fill this gap, asking the questions: How does individuals' access to social capital influence their perceived resilience to climate change? Do high levels of trust and affective ties among individuals' networks of family, friends, and neighbors (bonding social capital) limit individuals' resilience to climate change, as the literature would suggest? And conversely, do high levels of trust outside of individuals' close social networks (bridging social capital) increase individuals' capacity to adapt to changing circumstances? For both bonding and bridging social capital, does the quality of the social bond (i.e., trust) have more of an influence on perceived resilience than the quantity of ties an individual has? And how do various kinds of place-based social-psychological dependencies affect individual resilience? These are the fundamental questions asked in this research. They are specified in the following set of hypotheses:

$\mathrm{H}_{1}$ : The presence and use of individuals' bonding social capital will be negatively related to their willingness to learn about, plan for, and adapt to the impacts of climate change.

$\mathrm{H}_{2}$ : The presence and use of individuals' bridging social capital will be positively related to their willingness to learn about, plan for, and adapt to the impacts of climate change.

$\mathrm{H}_{3}$ : The strength of individuals' place-based social psychological dependence will be positively related to their willingness to learn about, plan for, and adapt to the impacts of climate change. 


\section{Methodology}

We tested the three hypotheses above with data collected through a mail questionnaire administered to residents living in three forest-associated communities located in western North Carolina. Data collection involved obtaining measurements for four distinct forms of social capital, seven separate types of place-based geographic dependence, and four hypothesized components of individual social resilience.

\section{Study Communities}

We selected three small, forest-associated communities within southern Appalachia (Spruce Pine, Waynesville, and Franklin) as the study populations. The 2010 population sizes of these three communities varied between 9,896 for Waynesville to 2,175 for Spruce Pine; the population of Franklin was 3,845 (U.S. Census Bureau 2012). These communities were selected because they all had been economically dependent on forest-based industries during the past several decades (defined as at least 10 percent employment in forest-related industries at one point between 1970 and 2010) and because each is currently surrounded by publicly managed forests (almost exclusively USDA Forest Service lands). Each of the three cities has transitioned from extractive forest or mining based economies to being primarily dependent upon regional tourism; all three communities have also experienced large increases in the number of individuals buying second homes and vacation properties (Smith 2011). The logic behind case selection was to select communities where individuals were likely to exhibit strong place-based social psychological dependence (residents in southern Appalachia are well-known for distinct local cultures strongly defined by the forest [Salstrom 1997]) and where future climate change would have an impact on both the local environment and the local economy.

\section{Measures}

To measure social capital, we asked respondents where they obtained information about local issues (associational ties) and how much they trusted (affective ties) the information received from those sources. We gave respondents 14 potential sources of community information and asked whether they received information from each source, and if so, the extent to which they trusted that information. We measured the bonding-associative form of social capital through respondents' indication of their use (scored 1) or nonuse (scored 0) of "close friends" or "immediate family" for information on local issues. We measured the 
bonding-affective form of social capital through respondents' indication of the extent to which they trusted the information obtained from "close friends" or "immediate family." We measured the bridging-associative form of social capital through the total number of informational sources (besides close friends and immediate family) used by respondents, and bridging-affective social capital through the aggregate level of trust respondents placed in information obtained from sources other than close friends or immediate family.

To measure place-based social-psychological dependencies, we used a 21-item scale designed to measure the seven distinct types of place meanings (Smith et al. 2011, 2012) described earlier, individual identity, family identity, self-efficacy, self-expression, community identity, economic dependence, and ecological dependence. Each meaning type is unobserved and measured by three to five measurement items (Table 1). We asked respondents to indicate their level of agreement with individual measurement items on a scale ranging from "strongly agree" (1) to "strongly disagree" (5).

We measured the hypothesized components of individual resilience through an 11-item scale developed using Marshall et al.'s guiding framework (Marshall et al. 2007, 2009). We measured each component, risk awareness, ability to learn, ability to plan, and ability to adapt, with two to four items (Table 2) and asked respondents to indicate their level of agreement with statements concerning increasingly severe weather, prolonged periods of drought, and physical changes to the forests near their community.

\section{Data Collection}

We drew a random sample of 300 full-time resident homeowners from tax records within each of the three communities (900 total households sampled). During the summer of 2011, we mailed questionnaires to potential respondents. We administered the questionnaires, which included the social capital measurement instrument, the place-meanings scale, and the individual resilience measurement instrument, according to the tailored design method (Dillman, Smyth, and Christian 2008). A total of 40 questionnaires were undeliverable. Of the successfully delivered questionnaires, 420 were returned completed (48.8 percent response).

\footnotetext{
${ }^{2}$ If respondents used that informational source, we asked whether they "always trusted information from that source" (coded 3), "sometimes trusted information from that source" (coded 2), or "did not trust information from that source" (coded 1). Responses were summed to generate measures.
} 


\section{Data Analysis}

Since the resilience scale introduced in this study has not been applied in previous empirical research, analysis proceeded through four distinct steps to maximize construct validity (Clark and Watson 1995). First, we generated an item pool based on a substantive literature review and 18 semistructured interviews conducted with political, civic, and religious leaders within the three study communities. We kept scale items conceptually broad enough to encompass the various components of resilience (perceiving risk, planning, learning, and adapting) described by interviewees and the existing literature. Second, following administration of the questionnaire, we tested each scale item for skewness and kurtosis (StataCorp 2009). Items with skewed data were removed from further analysis. Third, we used exploratory factor analysis to support discriminant validity among hypothesized resilience dimensions. Fourth, for each resilience dimension, we tested for internal reliability $(\alpha)$.

We used confirmatory factor analysis (CFA) on the place-meanings scale because previous research (Smith et al. 2011, 2012) supports the reliability and validity of the scale's seven-dimensional structure. Model fit was based on the following fit indices: a relative maximum likelihood chi-square $\left(\chi^{2} / \mathrm{df}\right)$ value less than 5.0 (Schumacker and Lomax 2004), a root mean-square error of approximation (RMSEA) near 0.06 with the upper limit of the 90 percent confidence interval at or below $0.08(\mathrm{Hu}$ and Bentler 1999), and a comparative fit index (CFI) and a Tucker-Lewis index (TLI) nearing 1.0 ( $\mathrm{Hu}$ and Bentler 1999).

Assuming both measurement models "fit" the data well as indicated through the above factor analyses, we estimate the structural coefficients between the latent variables within the structural model with a maximum-likelihood estimation procedure. We also explore the proposition that individuals' sociodemographic characteristics (age, education, gender, and income) are related to their perceived resilience to climate change, given that research on substantively different issues has found that controlling for sociodemographic characteristics mitigates the effects of social capital (Pitken 2008). We assess the fit of the structural model using the same criteria as in the previous CFA.

\section{Results}

\section{Sample Characteristics}

A comparison of each sample's sociodemographic characteristics revealed they were representative of their intended populations. The median age of respondents was 51 for Spruce Pine, 53 for Waynesville, and 55 for Franklin; these averages were not significantly different than U.S. 
census data on the age of owner-occupied housing units (Spruce Pine, $\chi^{2}(p)=0.051$; Waynesville, $\chi^{2}(p)=0.092$; Franklin, $\left.\chi^{2}(p)=0.076\right)$. Respondents tended to be male (74 percent, 69 percent, and 68 percent respectively). Respondents also tended to report household incomes between $\$ 35,000$ and $\$ 75,000$ (modal income categories were $\$ 35,000-\$ 49,999$, $\$ 50,000-\$ 74,999$, and $\$ 50,000-\$ 74,999$, respectively). Respondents were also predominantly white (97 percent, 99 percent, and 96 percent, respectively), a fact that did not differ from census data on housing-unit owners.

\section{Descriptive Statistics}

Initial analysis of the social capital measures indicates that the majority of respondents (92.9 percent) use either "close friends" or "immediate family" (bonding-associative ties) to obtain information about local issues. Respondents indicated they generally trust the information obtained from close friends (bonding-affective ties). Among respondents who obtain community information from close friends, 28.5 percent report always trusting that information while another 68.5 percent report sometimes trusting that information (3.0 percent of respondents indicate distrust in close friends). Similarly, respondents indicated they generally trust information obtained from immediate family members (bonding-affective ties). Of those using family members as an information source, 45.5 percent indicated always trusting their information and another 51.8 percent indicate sometimes trusting that information (2.8 percent indicated distrust).

Further analysis of the social capital measures reveals that individuals use a wide variety of sources to obtain information about community issues (Figure 1). Of the bridging connections, the most trusted source was churches, followed by local news sources, local civic groups, and extended family members. The least trusted informational sources were online nonnews sources, elected officials, and online news sources.

Table 1 provides descriptive statistics for the place-meanings scale. Initial analysis of the means and standard deviations reveals that local residents attach a diverse array of meanings to the forests surrounding their communities, as all scale-item means were above the neutral value of 3. The strongest meanings related to the forests' ecological importance $(M=4.48-4.59)$. Ecological meanings were also the most consistently ranked scale items $(\mathrm{SD}=0.94-0.95)$. The reliability of scale items relative to their hypothetical dimensions was acceptable $(\alpha \geq 0.90)$ and no single item reduced the internal reliability of its dimension $(\Delta \alpha<\alpha)$. Also, each statement item exhibited an acceptable $(\lambda>0.70)$ correlation with its latent dimension. 


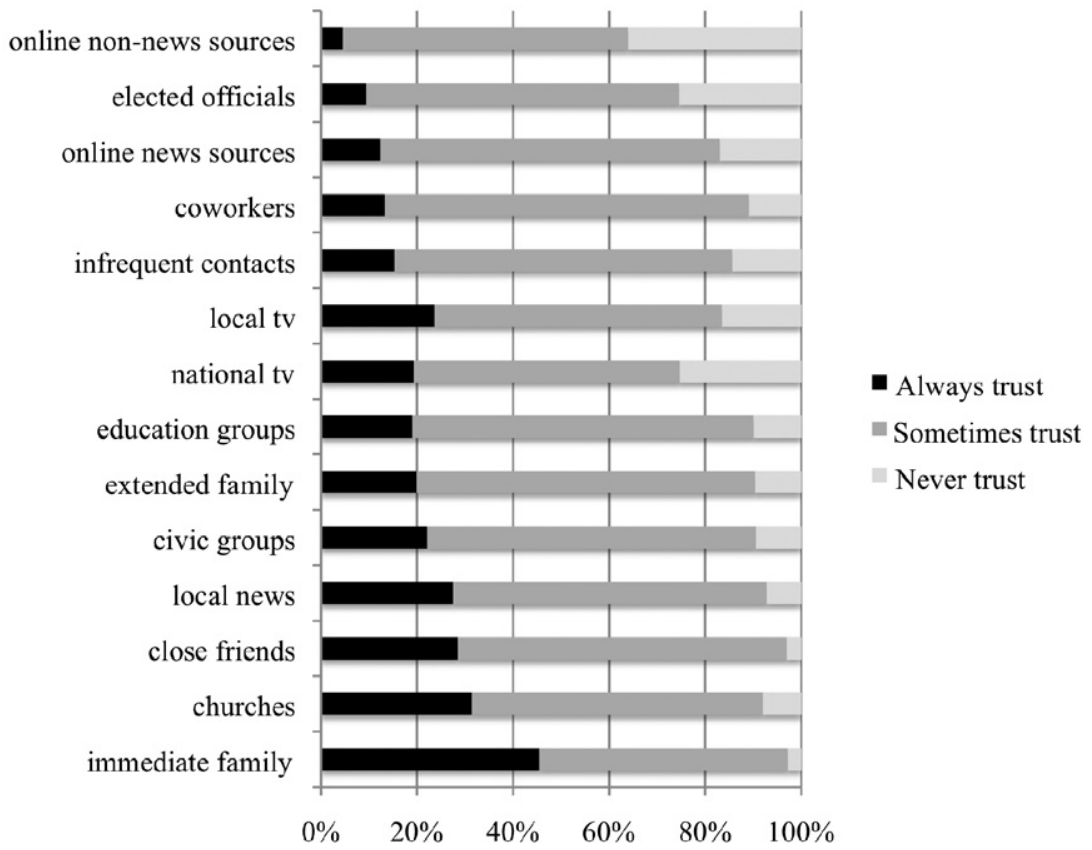

Figure 1. Level of Trust Placed in Sources for Local Community Information.

Table 2 gives descriptive statistics for the 11 items within the individual resilience scale. Generally, respondents agreed with statements suggesting they are at risk because of the consequences of climate change (grand $M=3.72$ on a five-point scale). Respondents also, on average, did not believe that information about the impact of climate change was easy to find (grand $M=2.78$ ). Respondents, by and large, believed they could plan for increasingly severe weather conditions or altered forest conditions (grand $M=3.60$ ). Perhaps as a result of these mixed appraisals, respondents, on average, were ambivalent about their ability to adapt to altered environmental and economic conditions (grand $M=3.13$ ).

\section{Psychometric Evaluation}

Following initial vetting of the resilience scale items for nonnormal distributions, a maximum-likelihood factor analysis with varimax rotation yielded a four-factor solution explaining 92.1 percent of the total 
Table 1. Descriptive Statistics for Place-Meanings Scale Items and Dimensions.

\begin{tabular}{|c|c|c|c|c|c|}
\hline Dimension and Statements & $M$ & SD & $\alpha$ & $\Delta \alpha$ & $\lambda$ \\
\hline Individual identity & & & 0.92 & & \\
\hline I am very attached to the forest & 4.01 & 1.11 & & 0.91 & 0.85 \\
\hline I feel this forest is a part of me & 3.70 & 1.11 & & 0.90 & 0.87 \\
\hline I identify strongly with the forest & 3.89 & 1.11 & & 0.86 & 0.92 \\
\hline Family identity & & & 0.90 & & \\
\hline I have pride in my heritage because of the forest & 3.86 & 1.15 & & 0.89 & 0.79 \\
\hline The forest is a special place for my family & 3.89 & 1.12 & & 0.84 & 0.87 \\
\hline Important family memories are tied to the forest & 3.75 & 1.18 & & 0.83 & 0.88 \\
\hline Self-efficacy & & & 0.90 & & \\
\hline The forest is best for the activities I like to do & 3.60 & 1.12 & & 0.86 & 0.88 \\
\hline periences when I visit the forest & 4.05 & 1.05 & & 0.88 & 0.83 \\
\hline compare to the forest & 3.78 & 1.13 & & 0.89 & 0.77 \\
\hline The forest is my first choice for outdoor recreation & 3.60 & 1.16 & & 0.87 & 0.84 \\
\hline Self-expression & & & 0.93 & & \\
\hline I feel that I can really be myself at the & 3.87 & 1.07 & & 0.91 & 0.87 \\
\hline allows me to express myself & 3.57 & 1.05 & & 0.87 & 0.92 \\
\hline Visiting the forest says a lot about who I am & 3.67 & 1.11 & & 0.91 & 0.87 \\
\hline Community identity & & & 0.93 & & \\
\hline The forest & 4.24 & 1.00 & & 0.91 & 0.89 \\
\hline The community's history is defined by the forest & 4.14 & 1.01 & & 0.88 & 0.93 \\
\hline The forest has helped put the community on the map & 4.10 & 1.03 & & 0.92 & 0.86 \\
\hline Economic meanings & & & 0.90 & & \\
\hline ity's economy depends on the & 3.79 & 1.02 & & - & 0.86 \\
\hline Appalachia's economy depends on the forest & 3.95 & 1.02 & & - & 0.86 \\
\hline Ecological meanings & & & 0.97 & & \\
\hline The forest is imnortant in conserving the landscone & 4.48 & 0.94 & & 0.96 & 0.92 \\
\hline & 4.59 & 0.95 & & 0.95 & 0.95 \\
\hline The forest is important in protecting water quality & 4.57 & 0.95 & & 0.94 & 0.96 \\
\hline
\end{tabular}

variance across the 11 scale items. Table 2 shows rotated factor loadings. The levels and their distinct heterogeneous grouping pattern illustrate support for each statement item, measuring its intended theoretical dimension (Hair et al. 2009). Each scale dimension also exhibited a "high" level of internal reliability $(\alpha>0.70$; Hair et al. 2009) and the removal of any single item did not decrease its dimension's reliability level $(\Delta \alpha<\alpha)$.

We next turned our attention to the place-meanings scale. Results from the confirmatory factor analysis, loading each of the 21 statement items on its a priori theoretical dimension, support the actual covariance matrix adequately fitting the matrix generated from the hypothesized seven-factor model (Table 3). Subsequently, we estimated the full measurement model (the seven-factor place-meanings scale and the four- 
Table 2. Descriptive Statistics for Perceived Resilience Scale Items and Dimensions.

\begin{tabular}{|c|c|c|c|c|c|c|c|c|}
\hline \multirow[b]{2}{*}{ Dimension and Scale Items } & \multirow[b]{2}{*}{ M } & \multirow[b]{2}{*}{$\mathrm{SD}$} & \multirow[b]{2}{*}{$\alpha$} & \multirow[b]{2}{*}{$\Delta \alpha$} & \multicolumn{4}{|c|}{ Rotated Factor Loadings ${ }^{\mathrm{a}}$} \\
\hline & & & & & $\lambda_{1}$ & $\lambda_{2}$ & $\lambda_{3}$ & $\lambda_{4}$ \\
\hline Risk perception & & & 0.93 & & & & & \\
\hline $\begin{array}{l}\text { I would be at risk if } \\
\text { increasingly severe } \\
\text { storms altered forest } \\
\text { conditions }\end{array}$ & 3.54 & 1.05 & & 0.92 & 0.826 & 0.118 & 0.085 & -0.061 \\
\hline $\begin{array}{l}\text { I would be at risk if } \\
\text { increasingly severe } \\
\text { droughts altered forest } \\
\text { conditions }\end{array}$ & 3.84 & 1.05 & & 0.86 & 0.930 & 0.141 & 0.008 & -0.050 \\
\hline $\begin{array}{l}\text { I would be at risk if } \\
\text { changing climatic } \\
\text { conditions altered } \\
\text { forest conditions }\end{array}$ & 3.77 & 1.02 & & 0.89 & 0.945 & 0.145 & -0.016 & 0.001 \\
\hline Ability to learn & & & 0.86 & & & & & \\
\hline $\begin{array}{l}\text { Information about } \\
\text { how changing } \\
\text { environmental } \\
\text { conditions impact the } \\
\text { forest is easy to find }\end{array}$ & 2.82 & 1.00 & & - & 0.083 & 0.115 & 0.851 & 0.038 \\
\hline $\begin{array}{l}\text { Information about how } \\
\text { forest conditions affect } \\
\text { my community is easy } \\
\text { to find }\end{array}$ & 2.73 & 0.96 & & - & -0.026 & 0.050 & 0.910 & 0.068 \\
\hline Ability to plan & & & 0.89 & & & & & \\
\hline $\begin{array}{l}\text { I could plan for } \\
\text { increasingly severe } \\
\text { weather conditions }\end{array}$ & 3.64 & 0.96 & & - & 0.190 & 0.836 & 0.087 & 0.066 \\
\hline $\begin{array}{l}\text { I could make plans if } \\
\text { forest conditions } \\
\text { changed }\end{array}$ & 3.56 & 0.91 & & - & 0.203 & 0.890 & 0.068 & 0.125 \\
\hline Ability to adapt & & & 0.63 & & & & & \\
\hline $\begin{array}{l}\text { I could adapt to } \\
\text { increasingly severe } \\
\text { weather conditions }\end{array}$ & 3.47 & 1.00 & & 0.56 & 0.034 & 0.444 & 0.092 & 0.496 \\
\hline $\begin{array}{l}\text { Things will turn out the } \\
\text { same for me, regardless } \\
\text { of forest changes }\end{array}$ & 2.45 & 1.10 & & 0.63 & -0.331 & -0.103 & 0.235 & 0.386 \\
\hline $\begin{array}{l}\text { I could adapt to altered } \\
\text { forest conditions }\end{array}$ & 3.16 & 0.91 & & 0.41 & -0.092 & 0.182 & 0.074 & 0.819 \\
\hline $\begin{array}{l}\text { I could cope with small } \\
\text { changes in } \\
\text { forest-related industries }\end{array}$ & 3.42 & 0.91 & & 0.59 & 0.079 & 0.165 & 0.071 & 0.445 \\
\hline $\begin{array}{l}\text { Proportion of variance } \\
\text { explained }(92.1 \% \text { of } \\
\text { total })\end{array}$ & & & & & 34.3 & 24.3 & 21.3 & 16.2 \\
\hline
\end{tabular}

${ }^{a}$ Maximum-likelihood factor method with Varimax rotation used to extract factors. Note. Each statement item's highest factor loading is indicated by boldface type. 
Table 3. Model-Fit Statistics for Measurement and Structural Models.

\begin{tabular}{lcccccc}
\hline & $\chi^{2}$ & $\mathrm{df}$ & $\chi^{2} / \mathrm{df}$ & RMSEA $(90 \%$ CI $)$ & CFI & TLI \\
\hline $\begin{array}{l}\text { Multigroup seven-factor } \\
\text { place-meanings } \\
\text { measurement model }\end{array}$ & 1157.27 & 492 & 2.35 & $0.06(0.06,0.07)$ & 0.92 & 0.90 \\
$\begin{array}{c}\text { Multigroup measurement } \\
\text { model }\end{array}$ & 2500.22 & 1299 & 1.93 & $0.05(0.05,0.06)$ & 0.89 & 0.87 \\
$\begin{array}{c}\text { (Seven-factor place-meanings } \\
\text { measurement instrument } \\
\text { and four-factor resilience } \\
\text { measurement instrument) }\end{array}$ & & & & & & \\
Structural model & 5673.20 & 1650 & 3.44 & $0.08(0.07,0.08)$ & 0.86 & 0.84 \\
\hline
\end{tabular}

factor resilience scale together) and recalculated model fit. The resulting fit statistics, shown in Table 3, suggest the data fit the modelimplied covariance matrix well.

Finally, we estimated the full structural model, which included the observed covariates associated with our four social capital measures. Estimation of the additional structural parameters and the addition of the observed covariates did not alter model fit substantially; the modelimplied covariance matrix fits the data well (Table 3). We also tested for whether the inclusion of individual sociodemographic characteristics improved model fit or altered the direction or significance of structural parameters; they did not (supplemental results provided in the Appendix).

\section{Structural Model Estimates}

Table 4 shows the coefficient estimates of structural paths. The results suggest both social capital and place-based social psychological dependence have a significant influence on individuals' perceived resilience to climate change.

Regarding specific types of social capital, the findings generally concur with social capital theory. The data suggest a significant and negative relationship between bonding-associative social capital and individuals' appraisals of their ability to learn about localized impact of climate change. Explicitly, respondents who use their close friends or immediate family to obtain information about local issues were significantly less likely $(\beta=-1.10$, std. $\beta=-0.11)$ to indicate that information about how changing environmental conditions affect their community and the surrounding forest is easy to find. 
Table 4. Structural Model Coefficients and Standard Errors.

\begin{tabular}{|c|c|c|c|c|c|c|c|c|}
\hline \multirow[b]{3}{*}{ Predictors } & \multicolumn{8}{|c|}{ Dependent Variables (Resilience Dimensions) } \\
\hline & \multicolumn{2}{|c|}{ Risk } & \multicolumn{2}{|c|}{ Learn } & \multicolumn{2}{|c|}{ Plan } & \multicolumn{2}{|c|}{ Adapt } \\
\hline & $\beta$ & (SE) & $\beta$ & $(\mathrm{SE})$ & $\beta$ & (SE) & $\beta$ & (SE) \\
\hline \multicolumn{9}{|l|}{ Social capital measures } \\
\hline Bonding associative & -0.09 & $(0.31)$ & $-1.10^{* * *}$ & $(0.27)$ & 0.48 & $(0.36)$ & 0.06 & $(0.07)$ \\
\hline Bonding affective & -0.01 & $(0.06)$ & 0.04 & $(0.04)$ & -0.10 & $(0.06)$ & -0.01 & $(0.01)$ \\
\hline Bridging associative & 0.02 & $(0.02)$ & $0.06^{* * *}$ & $(0.02)$ & -0.01 & $(0.02)$ & 0.01 & $(0.00)$ \\
\hline Bridging affective & -0.01 & $(0.01)$ & 0.02 & $(0.01)$ & 0.01 & $(0.01)$ & 0.01 & $(0.00)$ \\
\hline \multicolumn{9}{|l|}{ Place-meaning measures } \\
\hline Individual identity & 0.10 & $(0.07)$ & $0.13^{*}$ & $(0.06)$ & -0.16 & $(0.09)$ & -0.03 & $(0.04)$ \\
\hline Family identity & $0.33^{* * *} *$ & $(0.08)$ & $0.24 * * *$ & $(0.06)$ & -0.15 & $(0.08)$ & 0.01 & $(0.01)$ \\
\hline Self-efficacy & $0.53 * * *$ & $(0.08)$ & -0.05 & $(0.05)$ & $0.43^{* * *} *$ & $(0.09)$ & -0.01 & $(0.01)$ \\
\hline Self-expression & -0.09 & $(0.08)$ & $0.17 * *$ & $(0.06)$ & $0.27 * *$ & $(0.09)$ & 0.01 & $(0.01)$ \\
\hline Community identity & 0.02 & $(0.07)$ & $0.15^{* *}$ & $(0.06)$ & $0.18^{*}$ & $(0.08)$ & 0.03 & $(0.03)$ \\
\hline Economic meaning & -0.04 & $(0.08)$ & $0.17 * *$ & $(0.06)$ & $0.31^{* * * *}$ & $(0.09)$ & 0.02 & $(0.02)$ \\
\hline Ecological meaning & 0.36 *** & $(0.08)$ & $0.12^{*}$ & $(0.06)$ & 0.01 & $(0.09)$ & -0.04 & $(0.04)$ \\
\hline
\end{tabular}

$* p \leq .050, * * p \leq 0.010, * * * p \leq 0.001$.

Regarding bridging capital, the data suggest the number of bridging ties an individual has is significantly and positively related to that individual's ability to learn about the impact of climate change $(\beta=0.06$, std. $\beta=0.09$ ).

All of the types of place-based social psychological dependence measured through the place-meanings instrument had a significant influence on some component of individuals' perceptions of their climatechange resilience. Specifically, respondents who indicated their individual identity was heavily dependent on the local forest were more likely to indicate that climate-related information is easy to find $(\beta=$ 0.13 , std. $\beta=0.02$ ). Similarly, respondents who indicated their family's identity was strongly defined by the forest were significantly more likely to indicate that climate-related information is easy to find $(\beta=0.24$, std. $\beta=0.11$ ). Strong feelings of dependence on the forest for family identity were also significantly related to greater perceptions of climateassociated risks $(\beta=0.33$, std. $\beta=0.36)$.

Further analyses of structural model coefficients reveal that individual respondents who indicated they were dependent on the local forest to engage in desired activities (self-efficacy) were more likely to perceive climate-related risks $(\beta=0.53$, std. $\beta=0.58)$ and more likely to believe they could plan for those risks $(\beta=0.43$, std. $\beta=0.43)$. A similar, but distinct, type of place-based dependence is the need to use the forest for self-expression. Individuals who indicated a greater dependence on the forest for personal expression were more likely to indicate that climate- 
related information is easy to find $(\beta=0.17$, std. $\beta=0.07)$ and that they could plan for climate-related risks $(\beta=0.27$, std. $\beta=0.24)$.

The data also suggest that stronger appraisals of the connection between community and forest are related to appraisals of resilience. Individuals who believed their community's identity was heavily dependent on the forest were also more likely to indicate that climate-related information is easy to find $(\beta=0.15$, std. $\beta=0.07)$ and that they could plan for climate-related risks $(\beta=0.27$, std. $\beta=0.18)$.

The data also suggest that economic meanings attached to the forest are significantly related to individuals' willingness to learn about the potential impact of climate change $(\beta=0.17$, std. $\beta=0.07)$ and their beliefs about their ability to plan for future impact $(\beta=0.31$, std. $\beta=$ $0.30)$.

The final kind of place-based social psychological dependence related to perceived climate resilience was the belief that ecosystem characteristics were dependent on the health of the forest. Greater appraisals of ecological dependence were positively associated with both awareness of the risks associated with climate change $(\beta=0.36$, std. $\beta=0.34)$ and individuals' willingness to learn about the potential impacts of climate change $(\beta=0.12$, std. $\beta=0.07)$.

\section{Discussion}

\section{Summary}

While climate change has come to dominate the agendas of federal agencies as well as national and international research organizations, the sociologically informed literature on climate adaptation remains limited. By examining the effects of various types of social capital on individuals' levels of climate resilience, this research begins to fill this gap and provide a clearer understanding of the social process of resilience.

Regarding our first hypotheses, we found a negative relationship between bonding ties (associative) and individuals' ability to learn about the localized impacts of climate change. The data provide support for the theory that reliance on strong, highly bonded ties for information and resources can inhibit one's willingness to seek new information. Bonding social capital appears to limit knowledge-seeking behavior; however, whether that limitation translates into reduced adaptive capacities is a question that cannot fully be answered with the data collected here.

Regarding our second hypothesis, we found positive relationships between the stock of bridging social capital and individuals' willingness to learn about the potential impact of climate change. The data provide 
support for the theory that the availability and use of a diverse range of nonfriend, nonfamily social ties can provide the information and resources needed to learn about and plan for uncertain future environmental conditions. The more "weak" ties that an individual had (bridging-associative), the more likely the individual was to seek information related to the impact of local climate change. Individuals with a greater stock of bridging social capital appear to have a more diverse pool of knowledge and information from which to draw during the formation of their beliefs about climate change.

These two findings can inform the development and dissemination of strategies for adapting to climate change and, in turn, can maximize the resilience of rural communities (Salinger, Sivakumar, and Motha 2005). Community leaders and natural resource planners (USDA Forest Service employees in this study) should focus the dissemination of information related to climate change to highly trusted informational outlets such as churches, local newspapers or periodicals, and local civic groups. The dissemination of information through these sources is likely to have the greatest influence on individuals' knowledge of potential adaptation to climate change. Dissemination of information through more informal modes of communication, as opposed to more "top-down" modes of communication, also encourages collaborative learning (Bruckmeier and Tovey 2008). The capacity to learn collaboratively is a key determinant of community resilience, especially in smaller communities where adaptive behavior is more likely to require collective action (Anderson 2003; Flora 1998; Schusler, Decker, and Pfeffer 2003). The ultimate goal of these targeted extension and outreach efforts is to provide individuals with the capacities necessary to make incremental behavioral changes that enhance individual and community resilience (Stokes and Howden 2010).

Through the examination of our third hypothesis, we imply that resource dependence involves much more than an economic dimension for individuals living in the three communities rich in natural resources in the study. Rather, individuals are frequently dependent on the natural amenities surrounding their communities for a variety of reasons. We hypothesized these kinds of place-based social psychological dependence would be catalysts that could influence individuals' perceptions of risks of climate change, their willingness to learn about or plan for the impact of climate change, and their personal beliefs concerning their ability to adapt to these changes. Our data analysis provides support for this hypothesis.

Specifically, the data suggest individuals' place-based identity is positively related to their perceptions of climate risk and ability to learn 
about the impact of climate change. Similar feelings of place-based family identity were positively related to individuals' risk awareness and their ability to learn about the impact of such change. Individuals with stronger appraisals of individual and family identity have more to lose from altered climatic conditions and their subsequent impact on local forests. Logically, then, it follows that these individuals would be more willing to invest their personal time and resources to learn about the impact of climate change. Regarding both concepts of individual and family identity, the data support this logical assumption.

In a similar vein, individuals who are psychologically dependent on a local forest as an arena where they can express themselves as well as individuals who are behaviorally dependent on that forest to engage in desired activities should be more aware of climate risks and willing to learn, plan, and adapt to them. Our data partially bear out this proposition. We found feelings of self-expression to be positively related to both individuals' willingness to learn about the local impact of climate change and the belief they could plan for that future impact. Similarly, behavioral dependence (self-efficacy) on the forest was positively related to individuals' perceptions of climate-related risks and their perceived ability to plan for those risks. This finding suggests that the effect of climate change on activities for which individuals currently depend on the forest (e.g., hunting, family gatherings, recreation) could make individuals more aware of climate-related risks, make them more motivated to seek information regarding those risks, and motivate them to plan to adapt to any potential impact.

A community's identity can be highly intertwined with the geographic and ecological setting where that population resides. Arguably, the connection between a population's identity and its physical settings is one of the defining factors enabling "community" to emerge (Wilkinson 1999). Given this, one might expect individuals to be highly concerned with not only the biophysical impacts of climate change but also the consequences they could have for altering community identity. We could logically presume individuals who believe their community's identity is heavily defined by the surrounding forest to be acutely aware of the local impacts of climate change and, subsequently, to be more willing to learn about, plan for, and adapt to those changes. As hypothesized, these clear and positive associations were supported by our data. Individuals who believed their community's identity was more dependent on the forest were more likely to indicate that information about the local impacts of climate change is easy to find and that they are able to plan for those impacts. Similarly, feelings of a strong connection between local forests and economic health appear to influence appraisals of individual 
resilience. Specifically, individuals who believed their community, or the region as a whole, was economically dependent on the forest were more likely to believe that information concerning the localized impacts of climate change is easy to find; they also tended to express stronger beliefs about their willingness to plan for future impacts. Similarly, greater perceptions of ecological dependence on nearby forests were positively associated with greater perceptions of climate risks and greater willingness to learn about potential risks.

Collectively, the findings related to individuals' place-based socialpsychological dependence bear out two key implications. First, the data provide support for the hypothesis that social-psychological dependence can, and likely does, play an integral role in individuals' adaptation strategies. Adaptation involves more than just making physical and structural adjustments to one's community in response to environmental changes. Rather, adaptation also includes a range of psychological processes that both precede and follow actual behavioral responses (Reser and Swim 2011). The data collected here suggest these psychological processes are empirically distinct and include perceiving climate change as a risk, being willing to learn about and plan for potential impacts, and believing one can adapt. The data also suggest these psychological processes are influenced by individuals' cognitive appraisals of how dependent they and their communities are on local natural resources likely to be heavily affected.

The second key implication of these findings is their ability to highlight how variations in individuals' beliefs affect their perceptions of climate change and their ability to adapt. Swim and colleagues (2011) note that individuals' general worldviews, values, and beliefs shape cognitive appraisals of climate change, which in turn, shape behavioral responses. Our data suggest the place-based values that shape individuals' cognitive appraisals of climate change do not necessarily have to be intrapsychic, they can also extend to more generalized values concerning family and community. Specifically, we examined three socialpsychological meanings that pertain solely to the individual (individual identity, self-efficacy, self-expression) and found, by and large, they were positively related to perceptions of risks from climate change, the willingness to learn about climate change, and individuals' perceived ability to plan for the impact of change. This finding would be expected under nearly any theory of individual behavior (e.g., values-beliefs-norms theory, theory of planned behavior). However, we also examined four extrapsychic social-psychological meanings that pertain to individuals' family (family identity) and their community (community identity, economic meaning, ecological meaning) and found these meanings as well 
were positively related to perceptions of risk, the willingness to learn about climate change, and individuals' perceived ability to plan for climate-related impacts. Within the context of our study, these distinct types of meanings seemed intuitive. However, evidence suggesting both intra- and extrapsychic meanings influence perceptions of climate resilience could open new avenues for understanding what factors shape individuals' perceptions of climate change and its impacts. While several pieces of previous research (Heath and Gifford 2006; Weber 2010) illustrate how variations in individuals' personal values shape perceptions of climate change, our data suggest that more attention to how individuals' perceptions of social identities (e.g., family and community identity) and dependence (e.g., a community's economic or ecological dependence) influence perceptions of climate change and individuals' ability to adapt to uncertain environmental conditions is warranted.

\section{Conclusion}

While climate change has arguably become the most consequential political, economical, and social issue of contemporary society, little research on climate change has adopted a sociological perspective (Nagel et al. 2009). Furthermore, the sociologically oriented research that has been completed tends to look at macrostructural processes and the actions of nation-states in political and economic debates (e.g., Clark and York 2005; Rosa and Dietz 1998). Through this research, we have offered a complementary analysis by focusing solely on the individual as the acting agent being affected by climate change. We have drawn from literature that is both well established (place meanings and resource dependence) and emergent (resilience and coupled social-ecological systems) in an attempt to determine the characteristics of individuals that tend to make them more, or less, resilient to the impacts of climate change. Resilience theory has only relatively recently entered the lexicon of social scientists, being introduced via research on coupled socialecological systems (Gunderson and Holling 2002). However, it has great potential in bridging the traditional gaps between natural science and social science. Just as importantly, social capital theory has much to offer current research aimed at understanding if and how individuals can collectively address the causes and consequences of climate change. We believe that by developing a bridge between the theories of the natural sciences and the theories of the social sciences, new possibilities can emerge for future scholarship and, more importantly, potential solutions to the complex socioecological problems facing humanity today can be identified. By gaining a clearer understanding of how social 
capital and place-based social-psychological dependencies affect individuals' perceived ability to adapt to changing environmental conditions, community leaders and policymakers at various levels of authority will be better equipped to help foster a sustainable ecological and social future.

\section{Limitations}

One potential limitation of this research is the narrow measures used to gauge the social capital construct. Social capital is a robust concept with origins and applications in numerous disciplinary fields (Paldam 2000). As a result, multiple measurement approaches have been used, primarily to accommodate distinct observational units (e.g., individuals, groups, nation-states), methodological approaches (e.g., the use of survey research, secondary data, or social network analysis), and the availability of data (e.g., the widespread use of the presence of voluntary association groups as a proxy). Nearly universal in the diverse disciplinary literatures, however, are the two essential components of trust and objective network ties. We grounded the measurements developed for this study in these two components in an effort to gauge as many types of social capital (bonding, bridging, affective, and objective) as feasible. Other measurement approaches would be able to gauge more nuanced aspects of social capital, such as situational factors influencing the extent to which individuals trust others (Earle 2004) or community-wide norms of reciprocity (Jicha et al. 2011), that might influence individuals' willingness and ability to take actions in response to changing environmental conditions. Also, our measure of social capital was directed only at intracommunity information transmission. The diffusion of other resources, such as financial capital, through individuals' networks is also likely to influence individuals' climate-change resilience. In sum, our four-variable approach to social capital measurement does not gauge the full breadth of the construct's theoretical underpinnings, and it is unclear whether any measurement approach actually could (Paldam 2000). Our instrumentation does, however, address the fundamental components of trust and objective network ties universal to nearly all conceptualizations of the construct. 


\section{Appendix. Structural Model Coefficients and Standard Errors (With Sociodemographic Characteristics Included)}

\begin{tabular}{|c|c|c|c|c|c|c|c|c|}
\hline \multirow[b]{3}{*}{ Predictor } & \multicolumn{8}{|c|}{ Dependent Variable (Resilience Dimension) } \\
\hline & \multicolumn{2}{|c|}{ Risk } & \multicolumn{2}{|c|}{ Learn } & \multicolumn{2}{|c|}{ Plan } & \multicolumn{2}{|c|}{ Adapt } \\
\hline & $\beta$ & $(\mathrm{SE})$ & $\beta$ & $(\mathrm{SE})$ & $\beta$ & $(\mathrm{SE})$ & $\beta$ & (SE) \\
\hline \multicolumn{9}{|c|}{ Sociodemographic characteristics } \\
\hline Age & -0.01 & $(0.01)$ & 0.01 & $(0.01)$ & 0.01 & $(0.01)$ & 0.01 & $(0.01)$ \\
\hline Education & 0.02 & $(0.05)$ & 0.04 & $(0.06)$ & 0.01 & $(0.01)$ & -0.11 & $(0.10)$ \\
\hline Gender & 0.22 & $(0.16)$ & -0.16 & $(0.13)$ & 0.01 & $(0.19)$ & -0.03 & $(0.04)$ \\
\hline Income & 0.10 & $(0.09)$ & 0.01 & $(0.03)$ & 0.10 & $(0.09)$ & 0.01 & $(0.01)$ \\
\hline \multicolumn{9}{|l|}{ Social capital measures } \\
\hline Bonding associative & -0.63 & $(0.59)$ & $-1.38 * * *$ & $(0.26)$ & 0.81 & $(0.64)$ & 0.08 & $(0.08)$ \\
\hline Bonding affective & 0.04 & $(0.05)$ & 0.04 & $(0.04)$ & -0.07 & $(0.06)$ & -0.01 & $(0.01)$ \\
\hline Bridging associative & 0.04 & $(0.03)$ & $0.08 * * *$ & $(0.02)$ & -0.04 & $(0.02)$ & -0.01 & $(0.01)$ \\
\hline Bridging affective & 0.01 & $(0.01)$ & 0.02 & $(0.02)$ & 0.00 & $(0.01)$ & 0.01 & $(0.01)$ \\
\hline \multicolumn{9}{|l|}{ Place-meaning measures } \\
\hline Individual identity & 0.24 & $(0.14)$ & 0.04 & $(0.05)$ & -0.09 & $(0.08)$ & 0.01 & $(0.01)$ \\
\hline Family identity & $0.18^{* *}$ & $(0.07)$ & $0.36 * * *$ & $(0.07)$ & -0.25 & $(0.18)$ & 0.01 & $(0.01)$ \\
\hline Self-efficacy & $0.15^{*}$ & $(0.07)$ & -0.01 & $(0.05)$ & $0.79 * * *$ & $(0.08)$ & -0.01 & $(0.02)$ \\
\hline Self-expression & -0.26 & $(0.17)$ & 0.03 & $(0.05)$ & $0.78 * * *$ & $(0.09)$ & 0.01 & $(0.01)$ \\
\hline Community identity & 0.01 & $(0.07)$ & $0.19 * * *$ & $(0.05)$ & 0.04 & $(0.08)$ & 0.04 & $(0.04)$ \\
\hline Economic meaning & -0.02 & $(0.04)$ & 0.02 & $(0.03)$ & $0.03 * *$ & $(0.01)$ & -0.01 & $(0.01)$ \\
\hline Ecological meaning & $0.34 * * *$ & $(0.03)$ & 0.03 & $(0.06)$ & 0.16 & $(0.09)$ & -0.02 & $(0.03)$ \\
\hline
\end{tabular}

Model-fit Statistics: $\chi^{2}=6450.95, \mathrm{df}=2064, \chi^{2} / \mathrm{df}=3.125$, RMSEA $(90 \% \mathrm{CI})=0.08(0.08,0.08)$, CFI $=0.82, \mathrm{TLI}=0.80$.

$* p \leq .050, * * p \leq .010, * * * p \leq .001$.

\section{References}

Adger, W. Neil. 2003. "Social Capital, Collective Action, and Adaptation to Climate Change." Economic Geography 79(4):387-404.

Anderson, Jock R. 2003. "Risk in Rural Development: Challenges for Managers and Policy Makers." Agricultural Systems 75(2-):161-97.

Barber, Bernard. 1983. The Logic and Limits of Trust. New Brunswick, NJ: Rutgers University Press.

Bourdieu, Pierre. 1986. "The Forms of Capital." Pp. 241-58 in Handbook of Theory and Research for the Sociology of Education, edited by John G. Richardson. New York: Greenwood Press.

Breiger, Ronald. 1974. "The Duality of Persons and Groups." Social Forces 53:181-90.

Brewer, Jennifer, ed. 2009. New Directions in Climate Change Vulnerability, Impacts, and Adaptation Assessment: Summary of a Workshop. National Research Council. Washington, DC: National Academies Press.

Bruckmeier, Karl and Hilary Tovey. 2008. "Knowledge in Sustainable Rural Development: From Forms of Knowledge to Knowledge Processes." Sociologia Ruralis 48(3):313-29.

Carpenter, Stephen R. and Lance H. Gunderson. 2001. "Coping with Collapse: Ecological and Social Dynamics in Ecosystem Management." Bioscience 51:451-57.

Clark, Brett and Richard York. 2005. "Carbon Metabolism: Global Capitalism, Climate Change, and the Biospheric Rift." Theory and Society 34:391-428.

Clark, Lee Anna, and David Watson. 1995. "Construct Validity: Basic Issues in Objective Scale Development.” Psychological Assessment 7:309-19.

Coleman, James S. 1988. "Social Capital in the Creation of Human Capital." American Journal of Sociology 94:S95-120.

- 1990. Foundations of Social Theory. Cambridge, MA: Harvard University Press. 
Dillman, Don A., Jolene D. Smyth, and Leah Melani Christian. 2008. Internet, Mail, and Mixed-Mode Surveys: The Tailored Design Method. New York: Wiley.

Duncan, Otis Dudley. 1959. "Human Ecology and Population Studies." Pp. 681-85 in The Study of Population, edited by Philip M. Hauser and Otis Dudley Duncan, Chicago, IL: University of Chicago Press.

—. 1961. "From Social System to Ecosystem." Sociological Inquiry 31 (2):140-49.

Earle, Timothy C. 2004. "Thinking Aloud about Trust: A Protocol Analysis of Trust in Risk Management." Risk Analysis 24:169-83.

Flora, Jan L. 1998. "Social Capital and Communities of Place." Rural Sociology 63:481506.

Folke, Carl, Steven Carpenter, Thomas Elmqvist, Lance Gunderson, C. S. Holling, and Brian Walker. 2002. "Resilience and Sustainable Development: Building Adaptive Capacity in a World of Transformations." AMBIO: A Journal of Human Environment $31(5): 437-40$.

Frank, Ken. 2009. "Socially Embedded Environmental Action." Pp. 87-89 in Workshop on Sociological Perspectives on Global Climate Change, edited by Joane Nagel, Thomas Dietz, and Jeffrey Broadbent. Washington, DC: National Science Foundation. Retrieved January 31, 2010 (http://ireswb.cc.ku.edu/ crgc/NSFWorkshop/Report.html).

Gittell, Ross and Avis Vidal. 1998. Community Organizing: Building Social Capital as a Development Strategy. Thousand Oaks, CA: Sage.

Granovetter, Mark S. 1973. "The Strength of Weak Ties.” American Journal of Sociology 78(6):1360-80.

Gunderson, Lance. 1999. "Resilience, Flexibility, and Adaptive Management-Antidotes for Spurious Certitude?” Conservation Ecology 13(1). Retrieved January 31, 2010 (http://www.ecologyandsociety.org/vol3/iss1/art7/).

Gunderson, Lance and C. S. Holling, eds. (2002). Panarchy: Understanding Transformations in Human and Natural Systems. Washington, DC: Island Press.

Hair, Joseph F., William C. Black, Barry J. Babin, and Rolph E. Anderson. 2009. Multivariate Data Analysis. 7th ed. Englewood Cliffs, NJ: Prentice-Hall.

Hawley, Amos. 1950. Human Ecology: A Theory of Community Structure. New York: Ronald Press.

Heath, Yuko and Robert Gifford. 2006. "Free-Market Ideology and Environmental Degradation: The Case of Belief in Global Climate Change." Environment and Behavior 38:48-71.

Holling, C. S. 1973. "Resilience and Stability of Ecological Systems." Annual Review of Ecology and Systematics 4:1-23.

Howden, S. Mark, Jean-François Soussana, Francesco N. Tubiello, Netra Chhetri, Michael Dunlop, and Holger Meinke. 2007. "Adapting Agriculture to Climate Change." Proceedings of the National Academy of Sciences 104:19691-96.

$\mathrm{Hu}$, Li-tze and Peter M. Bentler. 1999. "Cutoff Criteria for Fit Indexes in Covariance Structure Analysis: Conventional Criteria versus New Alternatives.” Structural Equation Modeling 6:1-55.

Hughes, Terence P., David R. Bellwood, Carl Folke, Robert S. Steneck, and James Wilson. 2005. "New Paradigms for Supporting the Resilience of Marine Ecosystems." Trends in Ecology and Evolution 20(7):380-86.

Jicha, Karl A., Gretchen H. Thompson, Gregory M. Fulkerson, and Jonathan E. May. 2011. "Individual Participation in Collective Action in the Context of a Caribbean Island State: Testing the Effects of Multiple Dimensions of Social Capital.” Rural Sociology 76:229-56.

Jorgensen, Bradley S. and Richard C. Stedman. 2001. "Sense of Place as an Attitude: Lakeshore Property Owners' Attitudes toward Their Properties." Journal of Environmental Psychology 21:233-48.

— 2006. "A Comparative Analysis of Predictors of Sense of Place Dimensions: Attachment to, Dependence on, and Identification with Lakeshore Properties." Journal of Environmental Management, 79:316-27. 
Kyle, Gerard T., Alan R. Graefe, Robert E. Manning, and J. Bacon. 2003. “An Examination of the Relationship between Leisure Activity Involvement and Place Attachment among Hikers along the Appalachian Trail." Journal of Leisure Research 35:249-73.

Marshall, Nadine A., D. M. Fenton, Paul A. Marshall, and S. G. Sutton. 2007. "How Resource Dependency Can Influence Social Resilience within a Primary Resource Industry." Rural Sociology 72(3):359-90.

Marshall, Nadine A., Iain J. Gordon, and A. J. Ash. 2011. "The Reluctance of ResourceUsers to Adopt Seasonal Climate Forecasts to Enhance Resilience to Climate Variability on the Rangelands." Climatic Change 107:511-29.

Marshall, Nadine A., Paul A. Marshall, D. Obura, and J. Tamelander. 2009. A Framework for Social Adaptation to Climate Change: Sustaining Tropical Coastal Communities and Industries. Gland, Switzerland: International Union for the Conservation of Nature.

McAllister, Ryan R. J., Nick Abel, Chris J. Stokes, and Iain J. Gordon. 2006. "Australian Pastoralists in Time and Space: The Evolution of a Complex Adaptive System.” Ecology and Society 12. Retrieved January 31, 2010 (http://www.ecologyandsociety.org/vol11/ iss2/art41/).

Nagel, Joane, Thomas Dietz, and Jeffrey Broadbent, eds. 2009. Workshop on Sociological Perspectives on Global Climate Change. Washington, DC: National Science Foundation. Retrieved January 31, 2010 (http://ireswb.cc.ku.edu/ crgc/NSFWorkshop/ Report.html).

Nelson, Donald R., W. Neil Adger, and Katrina Brown. 2007. "Adaptation to Environmental Change: Contributions of a Resilience Framework." Annual Review of Environment and Resources 32:395-419.

Paldam, Martin. 2000. "Social Capital: One or Many? Definitions and Measurement." Journal of Economic Surveys 14:629-53.

Paxton, Pamela. 1999. "Is Social Capital Declining in the United States? A Multiple Indicator Assessment." American Journal of Sociology 105(1):88-127.

Pitken, Kathryn Derose. 2008. "Do Bonding, Bridging, and Linking Social Capital Affect Preventable Hospitalizations?" Health Services Research 43(5):1520-41.

Portes, Alejandro. 1998. "Social Capital: Its Origins and Applications in Modern Sociology." Annual Review of Sociology 24:1-24.

Proshansky, Harold M., Abbe K. Fabian, and Robert Kaminoff. 1995. "Place Identity: Physical World Socialization of the Self." In Giving Places Meaning: Readings in Environmental Psychology, edited by Linda N. Groat. London, England: Academic.

Putnam, Robert D. 2000. Bowling Alone: The Collapse and Revival of American Community. New York: Simon \& Schuster.

Reser, Joseph P. and Janet K. Swim. 2011. "Adapting and Coping with the Threat and Impacts of Climate Change." American Psychologist 66:277-89.

Rosa, Eugene A. and Thomas Dietz. 1998. "Climate Change and Society: Speculation, Construction and Scientific Investigation.” International Sociology 13:421-25.

Salinger, M. J., M. V. K. Sivakumar, and R. Motha. 2005. "Reducing Vulnerability of Agriculture and Forestry to Climate Variability and Change: Workshop Summary and Recommendations." Climatic Change 70:341-62.

Salstrom, Paul. 1997. Appalachia's Path to Dependency: Rethinking a Region's Economic History, 1730-1940. Lexington, KY: University of Kentucky Press.

Schumacker, Randall E. and Richard G. Lomax. 2004. A Beginner's Guide to Structural Equation Modeling. 2nd ed. New York: Psychology Press.

Schusler, Tania M., Daniel J. Decker, and Max J. Pfeffer. 2003. "Social Learning for Collaborative Natural Resource Management." Society and Natural Resources 16: 309-26.

Smith, Jordan W. 2011. "Adapting to Changing Environmental Conditions: MixedMethods Analyses of How Social Capital and Place-Based Social-Psychological Dependencies Influence Climate Change Resilience in Southern Appalachia.” PhD dissertation, Department of Parks, Recreation and Tourism Management, North Carolina State University, Raleigh, NC. 
Smith, Jordan W., Mae A. Davenport, Dorothy H. Anderson, and Jessica E. Leahy. 2011. "Place Meanings and Desired Management Outcomes." Landscape and Urban Planning 101(4):359-70.

Smith, Jordan W., Christos Siderelis, Roger L. Moore, and Dorothy H. Anderson. 2012. "The Effects of Place Meanings and Social Capital on Desired Forest Management Outcomes: A Stated Preference Experiment." Landscape and Urban Planning 106(2): 207-18.

StataCorp. 2009. “[R] Base Reference-sktest.” Pp. 1735-39 in Stata: Release 11, Statistical Software. College Station, TX: StataCorp, LP.

Stokes, Chris and Mark Howden, eds. 2010. Adapting Agriculture to Climate Change: Preparing Australian Agriculture, Forestry and Fisheries for the Future. Canberra, Australia: CSIRO.

Swim, Janet K., Paul C. Stern, Thomas J. Doherty, Susan Clayton, Joseph P. Reser, Elke U. Weber, Robert Gifford, and George S. Howard. 2011. "Psychology's Contributions to Understanding and Addressing Global Climate Change." American Psychologist 66:241-50.

Tuan, Yi-Fu. [1974] 1990. Topophilia: A Study of Environmental Perception, Attitudes, and Values. New York: Columbia University Press.

U.S. Census Bureau. 2012. "American FactFinder." Retrieved April 13, 2012 (http:// factfinder2.census.gov/faces/nav/jsf/pages/index.xhtml).

Wasserman, Stanley and Katherine Faust. 1994. Social Network Analysis: Methods and Applications. Cambridge, England: Cambridge University Press.

Weber, Elke U. 2010. "What Shapes Perceptions of Climate Change?" Wiley Interdisciplinary Reviews: Climate Change 1:332-42.

Wilkinson, Kenneth P. 1999. The Community in Rural America. Middleton, WI: Social Ecology Press.

Williams, Daniel R., Michael E. Patterson, Joseph W. Roggenbuck, and Alan E. Watson. 1992. "Beyond the Commodity Metaphor: Examining Emotional and Symbolic Attachment to Place." Leisure Sciences 14:29-46.

Woolcock, Michael. 1998. "Social Capital and Economic Development: Toward a Theoretical Synthesis and Policy Framework." Theory and Society 27:151-208.

—. 2003. "Social Capital." Pp. 1258-62 in Encyclopedia of Community, edited by Karen Christensen and David Levinson. Thousand Oaks, CA: Sage. 